\title{
CORRIGENDUM
}

\section{Dopaminergic function and intertemporal choice}

J Joutsa, V Voon, J Johansson, S Niemelä, J Bergman and V Kaasinen

Translational Psychiatry (2015) 5, e520; doi:10.1038/tp.2015.12; published online 3 March 2015

Correction to: Translational Psychiatry (2015) 4, e491; doi:10.1038/ tp.2014.133; published online 6 January 2015

Following publication of the above article, the authors were informed of an error in one of the figures. In Figure 1, the $r$ and
$P$-values were mixed between Figures $1 \mathrm{a}$ and $\mathrm{c}$, and between Figures $1 \mathrm{~b}$ and $\mathrm{d}$. The corrected Figure 1 is shown below. We thank Dr Guillaume Sescousse for informing us about the error.
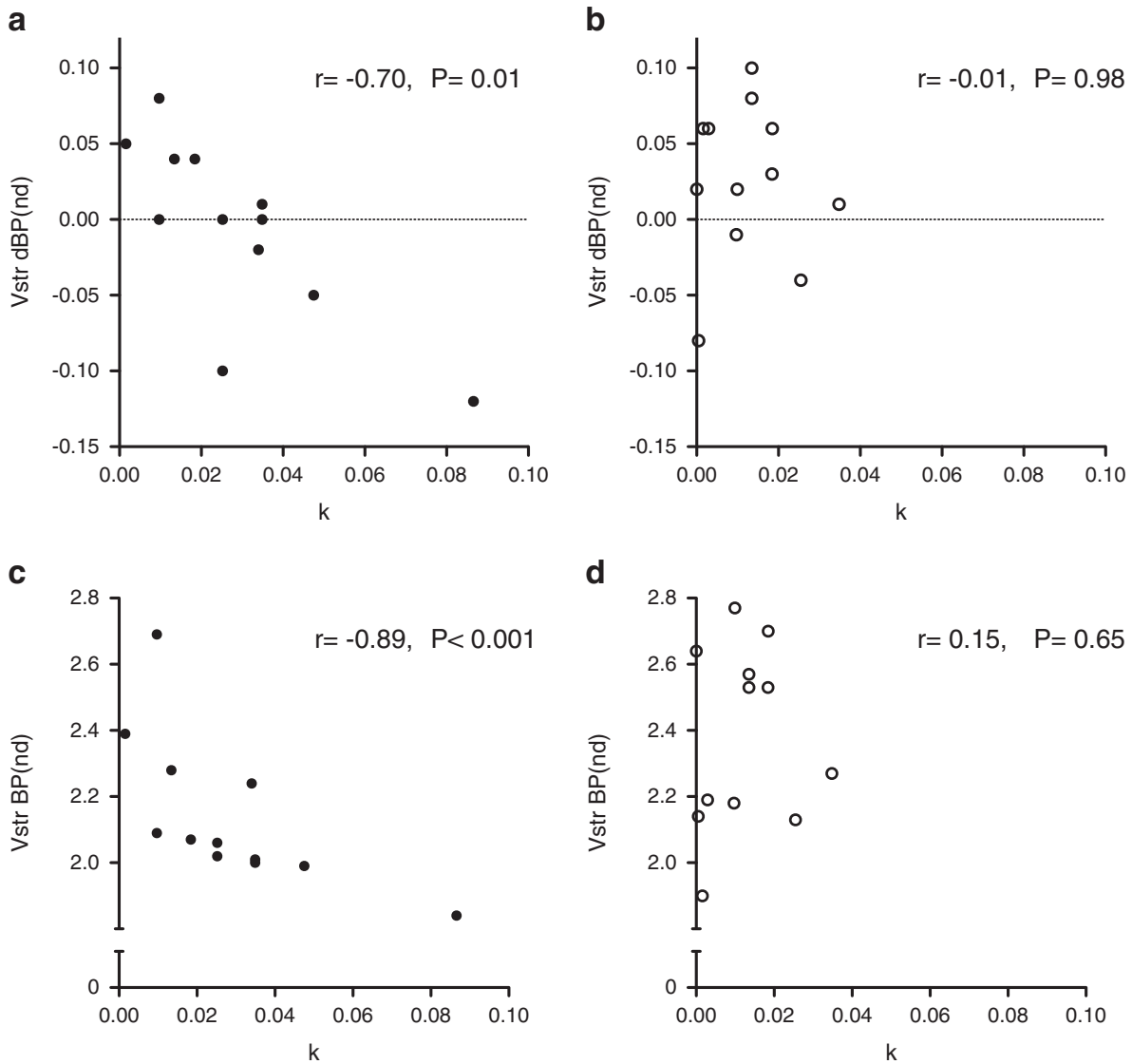

Figure 1. Temporal discounting and dopamine function in the ventral striatum. Spearman nonparametric correlations between temporal discounting rate $(k)$ and dopamine release $\left(V_{s t r} \mathrm{dBP}_{\mathrm{ND}}\right.$; positive values indicate dopamine release) in pathological gamblers (a) and controls (b). Correlations between the baseline ventral striatum D2/D3 availability (Vstr $\mathrm{BP}_{\mathrm{ND}}$ ) and $k$ in pathological gamblers (c) and controls (d). Solid circles represent PG subjects. Open circles represent healthy volunteers. $\mathrm{BP}_{\mathrm{ND}}$, non-displaceable binding potential; Vstr, ventral striatum; $\mathrm{PG}$, pathological gambling. 